\title{
Análise Semiótica da Linguagem Visual da música-aplicativo "Moon" do Álbum-aplicativo Didático "Biophilia" da Cantora Björk
}

\author{
Semiotic Analysis of the Visual Language of the Song App "Moon" from the Singer \\ Björk's Didactic App Album "Biophilia"
}

\author{
SALVARIO, Willian Batista; Estudante de Graduação; Universidade Positivo \\ wsalvario@gmail.com \\ VILELA, Thyenne Veiga; Mestre em Comunicação; Universidade Positivo \\ thyennevilela@gmail.com
}

\section{Resumo}

Esta pesquisa apresenta uma análise semiótica da linguagem visual da música-aplicativo Moon, do álbum-aplicativo didático Biophilia (2011), por meio do processo de tradução de linguagens. A fim de investigar relações construtivas entre três elementos: música, disciplinas propostas e composição visual - obteve-se o suporte teórico da Semiótica norte-americana (Peirce) e das Traduções Intersemióticas (Plaza). O aplicativo, concebido pela cantora islandesa Björk, baseia-se em seu álbum musical homônimo - com um aspecto multidisciplinar e multimídiático - tendo como premissa o ensino de temáticas do campo da Musicologia, Ciências Naturais e Humanidades. A análise ocorreu com a música-aplicativo Moon, devido a uma pré-análise com as dez músicasaplicativo. Para o estudo de tradução de linguagens, foi desenvolvido um sistema de Operação Tradutória dos componentes adotados - orientados pela relação de "Signo em Referência"; "Signo em Substituição"; e "Signo em Definição" - apresentando a tradução dos signos propostos sob metáforas visuais e simbólicas.

Palavras Chave: Design; Semiótica; Tradução de Linguagens.

\begin{abstract}
This research presents a Semiotic Analysis of the song app Moon's visual language, from the didactic app album "Biophilia" (2011), endeavoring to understand constructive relationships between music, suggested subjects and visual composition - related to the translation of languages - with the assistance of theoretical framework from Semiotics (Peirce) and Intersemiotic Translations (Plaza). The app album, created by the icelandic singer Björk (based on her homonymous album), discloses multidisciplinary and multimedia aspects, with proposals of teaching Musicology, Natural Sciences and Humanities. The song app analyzed was Moon, due to a previous analysis of each 10 song apps. For the study of the Translation of Languages, we developed an analytic ordering system about the Translation Procedure of the components and languages implemented, guided by the relation of "Signs in Reference"; "Signs in Substitution"; and "Signs in Definition" - examining the translation of signs proposed in the construction of its visual and symbolical metaphors.
\end{abstract}

Keywords: Design; Semiotics; Translation of Languages. 


\section{Introdução}

A tradução de linguagens se baseia no aspecto de "transmutação" da forma (Jakobson), ao consistir na interpretação de signos de um sistema sígnico de comunicação a outro meio, sistema ou contexto em tradução. A "transcriação" pode partir, por exemplo, dos signos verbais aos campos sonoros ou musicais, assim como à dança, cinema ou pintura (JAKOBSON apud PLAZA, 2001). A digitalização concede aos indivíduos a troca simultânea de informações mediante a união de meios tradicionais de suporte - ao ressaltar a inter-relação entre o campo sonoro, visual e verbal, tornando-se "linguagens híbridas", sendo definidos como as três grandes "matrizes da linguagem e pensamento" (SANTAELLA, 2001).

Devido à natureza de transmutação, esta pesquisa visa reconhecer oportunidades de análise da linguagem visual por meio do processo de tradução de linguagens - em relacionamento com o cenário musical e a materialidade visual - do álbum musical-interativo Biophilia (2011) (também denominado como um álbum-aplicativo) da cantora Björk, baseado no álbum musical homônimo. O Biophilia apresenta objetivos didáticos, para o ensino multidisciplinar de temas como Musicologia, Ciências Naturais e Humanidades. No entanto, para estudos em Comunicação e Design, as análises desta pesquisa foram estabelecidas acerca da transcrição de mídias, respondendo aos temas propostos, porém, sem o intuito de reconhecer a pragmática didática dessas temáticas. O álbum-aplicativo estabelece aspectos de linguagem pertinentes à compreensão da produção criativa, voltados ao campo da Comunicação Visual. São ao todo 10 canções existentes no álbum Biophilia, contudo, o estudo foi dirigido para a música-aplicativo "Moon". Neste artigo, ao ter em consideração o auxílio do suporte teórico da Semiótica e da Percepção Visual, explora-se o potencial de qualidade analítica e o rendimento acerca da articulação, complexidade e densidade dos conteúdos abordados nesta música-aplicativo.

Para responder à análise, este trabalho compreende a contextualização de Björk e o Biophilia, com seu objetivo de extensão didática e de educação tecnológica do projeto; desenvolve-se também uma fundamentação ao referencial teórico a respeito da Semiótica norteamericana e da Tradução Intersemiótica - esta como metodologia de análise e, por fim, a composição e definição do corpus da pesquisa. Como resultado, as diretrizes desenvolvidas consideram a articulação entre as temáticas as quais fundamentam a construção da materialidade visual do álbum-aplicativo - como letra musical; teoria musical; disciplina e temáticas de ciências naturais - em um processo de tradução de linguagens.

\section{Björk e Biophilia em contexto: o sétimo álbum musical da cantora Björk}

A artista islandesa Björk Guðmundsdóttir, conhecida por Björk, possui notoriedade em ser considerada uma cantora de estilo eclético, de letras com conteúdo lírico excêntrico, além de ser engajada às multifaces da música experimental - aplicadas ao contexto do cenário pop e de tecnologias musicais e audiovisuais (MILLER, 2008).

Björk concebeu seu sétimo e ambicioso álbum conceitual Biophilia (2011), com o objetivo de explorar música, natureza, humanidades e ciência em sua composição. O álbum possui uma espécie de marca baseada em um símbolo de compasso musical, o qual é utilizado em todo o material gráfico, servindo também como um botão de navegação no "álbum-aplicativo" homônimo (FIG. 1). De modo musical, o Biophilia é estruturado por temáticas - Musicologia, Ciências Naturais e Humanidades - enfatizadas e compostas em cada uma das 10 canções do álbum por meio de sua letra musical, do instrumental e também de seus títulos - como forma de 
descrição geral acerca das conexões conceituais entre os temas abordados (BIOPHILIA EDUCATIONAL, [2017]; BJORK.FR, [2011], tradução do autor).

FIGURA 1 - Capa de "Biophilia" (2011) e sua respectiva marca.
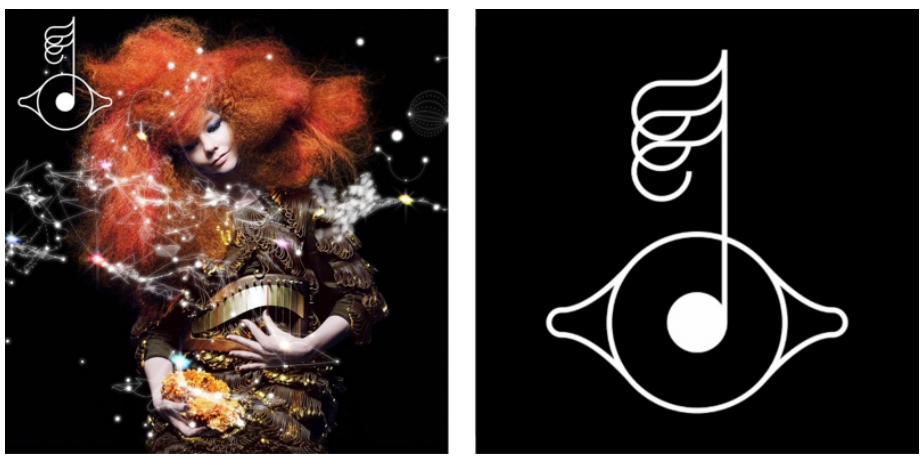

FONTE: https://www.amazon.com/Biophilia-Bjork/dp/B005ELQVGW; http://logos.wikia.com/wiki/Björk. Acesso em 8 abr. 2017.

O projeto merece atenção pelo seu caráter de multimídia, uma vez que que é considerado o "primeiro álbum-aplicativo em colaboração com a Apple" (SMITH, 2011, tradução do autor). Portanto, é um projeto em que abrange com amplitude diversos temas e atividades em meio digital e multimidiático. O álbum Biophilia, segundo o editorial da revista DAZED\&CONFUSED (2011),

[...] engloba sua música, instalações e concertos ao vivo celebrando o uso da tecnologia moderna por meio da utilização da internet. O projeto visa explorar ideias sobre como o som funciona, a infinita vastidão do universo; desde os sistemas planetários às estruturas atômicas. (DAZED\&CONFUSED, 2011, tradução do autor). ${ }^{1}$

\subsection{Biophilia em Extensão como Um Projeto Didático}

O álbum-aplicativo Biophilia faz parte do projeto denominado como Biophilia Educational Project. De acordo com o Biophilia Educational ([2017], tradução do autor), é um projeto construído com o auxílio da participação de estudiosos, cientistas e artistas abrangendo todos os níveis acadêmicos - contando também com o manual de diretrizes intitulado Learnteach, para apresentar o projeto do álbum-aplicativo acerca de seus aspectos educacionais e disciplinas presentes nas músicas-interativas. A partir de seu lema Listen, learn and create! ("Escute, aprenda e crie!" em português), o projeto tem como sua base a criatividade como ferramenta de pesquisa ao gerar inovação por meio da união entre música, tecnologia e ciências naturais - visando inspirar crianças de idades entre 10 a 12 anos, também incluir alunos de até 15 anos.

O álbum-aplicativo tem sua disponibilização para as plataformas iOS e também para Android, contando também com a coordenação do artista de interfaces interativas Scott Snibbe. Portanto, as músicas que compõem o aplicativo são Moon; Thunderbolt; Crystalline; Cosmogony

\footnotetext{
${ }^{1}[. .$.$] endeavour encompasses her music, installations and live shows, and celebrating the use of modern technology by$ utilising the internet. The project aims to explore ideas like how sound works, the infinite expanse of the universe, from planetary systems to atomic structure" (DAZED \& CONFUSED, 2011).
} 
(com exceção a esta canção, uma vez que tem o caráter de ser o "aplicativo-mãe" em que engloba todos os demais); Dark Matter; Hollow; Virus; Sacrifice; Mutual Core e Solstice (sendo aqui elencadas com base na ordem do disco e não conforme o aplicativo) - cada uma possuindo um aplicativo-interativo o qual contempla as propostas e relações de temáticas específicas para sua construção (BJORK.FR, [2011]; SNIBBE, 2011, tradução do autor).

\section{A Teoria Semiótica e a Tradução Intersemiótica}

Ao abordar sobre signos, Plaza (2001) descreve que para Peirce (semiótica norteamericana), os pensamentos têm sua condução por meio de três classes de signos - o ícone, o índice e o símbolo - sendo que possuem como sua finalidade melhorar ou complementar as palavras em relação à sua incompletude em significado. O próprio pensamento já é "intersemiótico", uma vez que os diferentes tipos de signos servem "[...] para trazer à mente objetos de espécies diferentes daqueles revelados por uma outra espécie de signos" (PEIRCE, [19-] apud PLAZA, p.21).

Por meio dos estudos de Peirce, reconhece-se que as linguagens, assim como o pensamento, possuem três aspectos importantes: “a) as suas qualidades materiais que dão ao pensamento sua qualidade; b) a aplicação denotativa ou conexão real que põe um pensamentosigno em relação a outro; c) a função representativa" (PEIRCE, [19--] apud PLAZA, 2001, p.21). Segundo Plaza (2001), Peirce cria a distinção entre as qualidades materiais do signo, seu objeto e seu significado, estabelecendo que a operação de todos os processos sígnicos são por meio de "relações triádicas" entre as três classes de signos que compõem os elementos de "semiose", sendo então denominados as três classes de signos como "ícone", "índice" e "símbolo". Os signos possuem diferentes naturezas, diferindo-se entre suas qualidades, materialidades, sua relação com o seu objeto e também com seus interpretantes. Ao se referir ao signo em relação ao seu objeto, Plaza (2001) acentua o interesse maior nos ícones, índices e símbolos para o seu pensamento sobre a Tradução Intersemiótica - como metodologia de análise para traduções sígnicas.

A Intersemiótica é, segundo Jakobson (apud PLAZA, 2001, n.p.), uma "transmutação" - no sentido de tradução - consistindo na interpretação dos signos de um sistema sígnico a outro, por exemplo, dos signos verbais para os campos sonoros, musicais, assim como também para as artes da dança, cinema ou pintura. O signo tem em si o poder de transição entre o pensamento interior e o exterior; possibilitando transpor o que se está na mente à outra expressão sígnica. Ao colocar o signo em foco ao relacionamento com as Matrizes da Linguagem, definidos por Santaella (2001) como a "sonora", a "visual" e a "verbal" - é possível perceber que "a lógica visual pode se manifestar em signos verbais ou sonoros, tanto quanto a sonoridade pode adquirir formas que a aproximam dos signos plásticos ou da discursividade própria do verbal" (SANTAELLA, 2001, p. 371).

Deste modo, a Tradução Intersemiótica trabalha por meio do conceito das três classes de signos de Peirce - icônico, indicial e simbólico - sendo preciso estabelecer um mapa de orientação a respeito das nuances dos processos de tradução. Com isto, Plaza (2001) instaura três tipologias como referência, salientando seu objetivo de instrumentalizar o processo de traduções, já que as diferentes classes podem atuar de modo simultâneo em uma mesma tradução. Como premissa teórica para a análise, compreende-se aqui uma síntese a respeito da Tradução Intersemiótica - a qual trabalha com três tipologias de tradução, segundo Plaza (2001): 
Tradução Icônica: atua por meio da similaridade de estrutura, criando analogias. Tem aptidão para criar significados com forma de qualidade e aparências. Tendo a possibilidade de ser "isomórfica" (ao admitir que diferentes substâncias se cristalizem em um mesmo sistema, tendo correspondência ou semelhança entre estruturas) ou "paramórficas" (ao se mostrar sob forma similar ou equivalente ao primeiro, podendo possuir estrutura diferente e equivalente, isto é, admitindo grande variedade de formas em organismos diferentes).

Tradução Indicial: pauta-se pela relação de contato entre o original e a tradução. Há continuidade entre ambas visto que possuem estruturas transitivas, isto é, o "Objeto Imediato" (objeto tal como é a sua representação) é apropriado e deslocado para outro meio. Aceitam-se aqui duas tipologias, sendo a "topológica-homeomórfica" (ao se trabalhar com a noção total de uma estrutura como correspondência simultânea em outro âmbito, ou seja, os dois conjuntos são equivalentes) e a "topológica-metonímica" (ao se trabalhar com a noção parcial de uma estrutura, como forma de instituir a continuidade entre o original e tradução, pelo deslocamento parcial para um novo contexto sígnico).

Tradução simbólica: baseia-se na tradução mediante a continuidade instituída, sendo assim realizada por metáforas, símbolos ou outros signos de caráter convencional (isto é, aprendidos por hábito). A tradução simbólica prioriza os significados (sendo mais lógicos, abstratos e intelectuais) do que sensíveis. Atua com a tomada dominante de um aspecto simbólico, desviando-se dos aspectos de essência original do "Objeto Imediato".

A fim de evidenciar a construção poética da linguagem da música-aplicativo Moon, o estudo das Traduções Intersemiótica favorece a consciência de que o signo tem a função de representar o seu objeto, colocando-se em seu lugar, tendo características e qualidades materiais próprias. Relacionando-se tanto com seu objeto quanto com seus interpretantes, os signos criam na mente de um indivíduo um signo equivalente ou um novo, e mais desenvolvido, significado (PLAZA, 2001).

\section{A Música-aplicativo Moon}

"Moon" é a primeira faixa musical no álbum Biophilia e o quarto single promocional lançado em videoclipe para divulgação. Visto que cada música retrata uma relação de temáticas, Moon explora a Astronomia (retratando sobre fases lunares, marés, ciclos sobre o corpo), o efeito que possuem sobre a terra e as pessoas, assim como a relaciona como o ciclo natural da vida, falha e sucesso - a fim de estabelecer uma conexão com sequências e estruturas musicais (BIOPHILIA EDUCATIONAL, [2017], tradução do autor). A respeito da mescla temática e da proposta conceitual da música-aplicativo, Björk [2011] explica que:

Com cada lua nova nós completamos um ciclo e nos é oferecida a renovação correr riscos, conectar-se a outras pessoas, amar, doar-se. O simbolismo da lua está presente como o campo da imaginação, da melancolia, e a regeneração é expressa na canção e música-aplicativo Moon por meio dos padrões musicais e imagens visuais das quais oscilam em mudança de fases, assim como pela letra musical sobre renascimento. ${ }^{2}$ (BJÖRK, [2011], tradução do autor).

\footnotetext{
${ }^{2}$ With each new moon we complete a cycle and are offered renewal - to take risks, to connect with other people, to love, to give. the symbolism of the moon as the realm of imagination, melancholy, and regeneration is expressed in the moon song and app by musical patterns and visual images which wax and wane, and by lyrics about rebirth (BJÖRK, [2011]).
} 
Como complemento, tem-se abaixo a captura de tela da música-aplicativo (Fig. 2):

FIGURA 2 - Captura de tela da composição visual de "Moon"

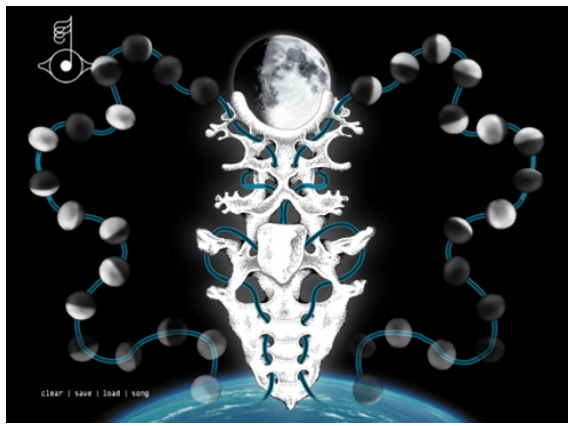

FONTE: Wellhart Ltd, presente no press kit de Scott Snibbe. Disponível em: http://www.snibbe.com/apps - /biophilia/. Acesso em: 1 set. 2017.

Por meio da letra musical de Moon, (FIG. 3), evidencia-se a construção do eu-lírico mediante uma visão melancólica sobre os ciclos em começos e términos, sejam humanos, emocionais ou de fenômenos naturais. A letra musical foi composta por Björk em parceria de Damian Taylor; a direção e produção de arte do videoclipe por Björk, Inez and Vinoodh, o estúdio de design M/M Paris e James Merry e, por fim, a música-aplicativo foi desenvolvida por Max Weisel. Björk propõe, então, um relacionamento ininterrupto e relacional entre a emoção, elementos de ciências naturais (envoltos ao misticismo e simbolismo) e a musicologia proposta (sequências musicais) por meio da elaboração poética e metafórica acerca da lua (BJÖRK apud STOSUY, 2011; BJÖRK, 2011, tradução do autor).

FIGURA 3 - Letra musical de "Moon"

\begin{tabular}{|c|c|}
\hline MOON & LUA \\
\hline $\begin{array}{l}\text { As the lukewarm hands of the gods } \\
\text { Came down and gently picked my } \\
\text { adrenalin pearls } \\
\text { Placed them in their mouths } \\
\text { And rinsed all the fear out } \\
\text { Nourished them with their saliva }\end{array}$ & $\begin{array}{l}\text { Como se as mornas mãos dos deuses } \\
\text { Viessem gentilmente e colhessem minhas } \\
\text { pérolas de adrenalina } \\
\text { Pusessem-nas em suas bocas } \\
\text { E enxaguassem todo o medo } \\
\text { Nutrindo-as com sua saliva }\end{array}$ \\
\hline $\begin{array}{l}\text { Rested } \\
\text { As if the healthiest past time } \\
\text { Is being in life-threatening circumstances } \\
\text { And once again be reborn }\end{array}$ & $\begin{array}{c}\text { Descansado } \\
\text { Como se o passatempo mais saudável } \\
\text { Fosse correr risco de morte } \\
\text { E renascer mais uma vez }\end{array}$ \\
\hline All birthed and happy $(4 x)$ & Todos nascidos e felizes ( $4 x$ ) \\
\hline
\end{tabular}




\begin{tabular}{|c|c|}
\hline $\begin{array}{l}\text { Best way to start-a-new } \\
\text { Is to fail miserably } \\
\text { Fail at loving } \\
\text { And fail at giving } \\
\text { Fail at creating a flow } \\
\text { Then realign the whole } \\
\text { And kick into the start hole }\end{array}$ & $\begin{array}{c}\text { A melhor forma de se recomeçar } \\
\text { É falhar miseravelmente } \\
\text { Falhar em amar } \\
\text { Falhar em doar-se } \\
\text { Falhar em criar um fluxo } \\
\text { E então realinhar-se por inteiro } \\
\text { E voltar ao principio }\end{array}$ \\
\hline $\begin{array}{l}\text { And kick into the starthole } \\
\text { And kick into the starthole }\end{array}$ & $\begin{array}{l}\text { Evoltar ao princípio } \\
\text { E voltar ao principio }\end{array}$ \\
\hline $\begin{array}{l}\text { To risk all is the end all and the beginning all } \\
\text { To risk all is the end all and the beginning all }\end{array}$ & $\begin{array}{l}\text { Arriscar tudo é o fim de tudo e o início de tudo } \\
\text { Arriscar tudo é o fim de tudo e o início de tudo }\end{array}$ \\
\hline
\end{tabular}

FONTE: http://genius.com/Bjork-moon-lyrics/. Tradução do autor. Acesso em: 22 mai. 2017.

Considerando as temáticas abordadas em Moon - tanto na análise da letra musical quanto na análise de elementos de sua composição visual - estabelecem-se Eixos Temáticos para o regimento analítico do processo tradutório da linguagem visual da música-aplicativo, conforme subcapítulo a seguir.

\subsection{Eixos Temáticos da música-aplicativo "Moon"}

Os Eixos Temáticos visam um mapeamento sobre referências visuais de temáticas educacionais da música-aplicativo Moon (astronomia, ciclos e sequências musicais) - procurando reconhecer vertentes para um olhar contemplativo acerca das linguagens adotadas na construção de sua materialidade visual. Para isto, instituem-se 5 Eixos Temáticos: Astronomia; Oceanografia (Biológica e Física); Biologia (Anatomia e Entomologia); Psicologia e Teoria Musical. Ressalta-se também que Astronomia, Oceanografia e Biologia são temáticas inerentes aos itens de sua composição visual, contudo, Psicologia e Teoria Musical são externas à visualidade - porém presentes na letra musical, na temática didático-musical e na interação da música-aplicativo.

Apenas o Eixo Temático da Oceanografia (Biológica) será analisado neste artigo, com base no sistema de Operação Tradutória proposto, devido à extensão e densidade das análises das demais temáticas (FIG. 4).

FIGURA 4 - Eixos Temáticos em "Moon"
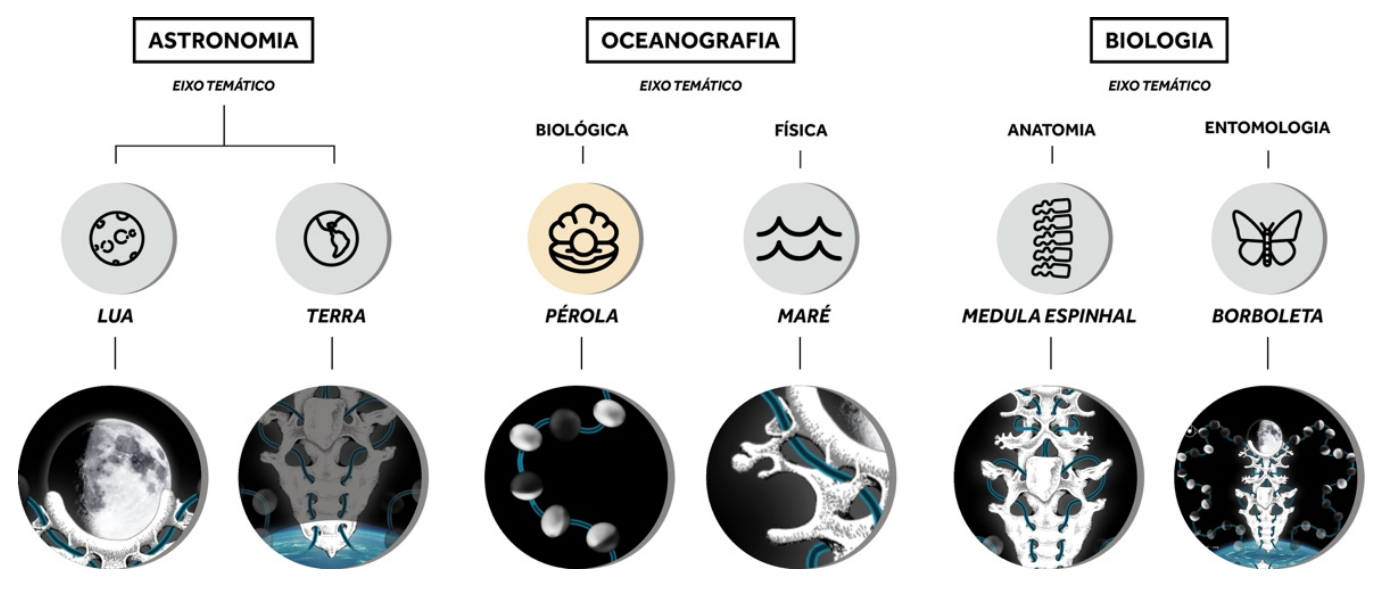
FONTE: Adaptado de Wellhart Ltd, presente no press kit de Scott Snibbe. Disponível em: http://www.snibbe.com/apps - /biophilia/. Elaborado pelo autor.

É ainda pertinente elencar os componentes visuais pertencentes à composição visual traduzida da música-aplicativo Moon, com base nos Eixos Temáticos desenvolvidos, sendo estes: Lua (Astronomia); Terra (Astronomia); Pérola (Oceanografia Biológica); Maré (Oceanografia Física); Medula Espinhal (Biologia - Anatomia) e Borboleta (Biologia - Entomologia).

Apesar do reconhecimento das temáticas de Psicologia e Teoria Musical, estes Eixos Temáticos não serão aprofundados em análises visto que sua abordagem não está atrelada, de modo direto, à representação visual da composição de Moon. Uma exploração a respeito dessas ramificações seria sugerida a futuras análises por parte de pesquisadores de áreas mais próximas ou a futuras pesquisas advindas desta análise semiótica.

\section{Desenvolvimento de Análises: Diretrizes para o Regimento Analítico da Música- aplicativo Moon}

A apresentação de dados foi disposta em um sistema de análise pautado no processo de "Operação Tradutória" dos elementos e linguagens adotadas, e por fim materializados em uma nova linguagem dentro da música-aplicativo selecionada (Fig. 5).

FIGURA 5 - Captura de tela da composição visual de "Moon"

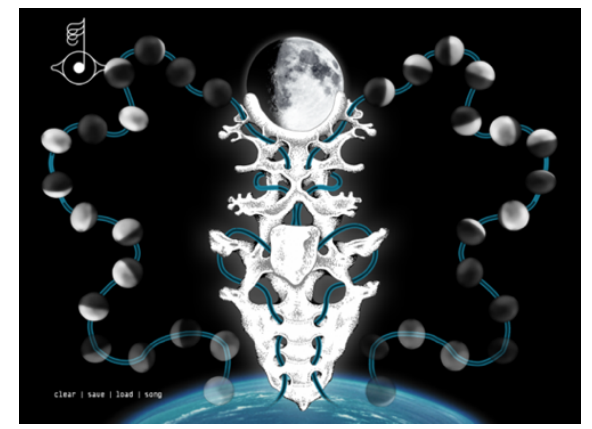

FONTE: Wellhart Ltd, presente no press kit de Scott Snibbe. Disponível em: http://www.snibbe.com/apps - /biophilia/. Acesso em: 1 set. 2017.

O sistema de análise do processo de tradução apresenta a seguinte composição, a relação de "Signo em Referência": elementos de composição advindos das diferentes linguagens e temáticas empregadas: disciplinas, letra musical e teoria musical - considerando o termo "Referência" por um de seus significados no dicionário: "Alusão a certa obra; menção a um determinado fato ou trecho" (MICHAELIS, 2017); "Signo em Substituição": um "Interpretante Dinâmico" - a interação entre diversos itens a fim da criação de outros significados (TURIN, 2007); e "Signo em Definição": a concretização de um um ressignificado aplicado na linguagem visual da música-aplicativo, pelo processo de substituição e complementação de qualidades significantes, derivadas dos diversos elementos utilizados - com base no termo "Definição" por um de seus significados no dicionário: "[...]Mecanismo linguístico que procura determinar clara e 
precisamente um conceito ou objeto." (DICIO, 2017) (FIG. 6).

\section{FIGURA 6 - Modelo de sistema de análise do processo de Operação Tradutória}

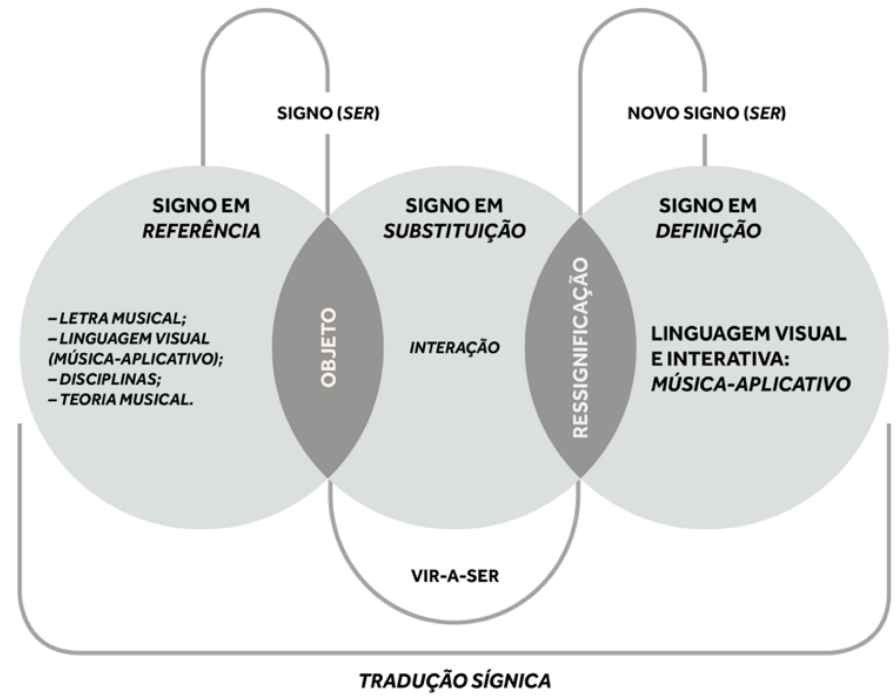

FONTE: Elaborado pelo autor.

O próximo subcapítulo tem como objetivo a análise exploratória de cada elemento compositivo da linguagem visual da música-aplicativo Moon, especificamente com o Eixo Temático da Oceanografia (Biológica). Resgatam-se diferentes contextos construtivos, de significados, e componentes visuais, por meio da estrutura apresentada pelo sistema de "Operação Tradutória": Signo em Referência; Signo em Substituição e Signo em Definição. Cabe ainda salientar de que ao longo do texto as palavras-chave estarão em negrito e itálico, a fim de contribuir para com o reconhecimento e evidenciação da narrativa a partir dos signos-chave da análise.

\subsection{O Eixo Temático de Oceanografia (Biológica): Uma Análise Sobre As Pérolas em "Moon"}

A Oceanografia Biológica, segundo UERJ [2017, n.p.], é uma ciência que visa o "estudo das inter-relações dos organismos vivos com os ambientes que habitam, ambientes estes oceânicos, costeiros e transicionais, como manguezais e estuários, com ênfase nas relações ecológicas". Tendo em vista os elementos presentes na composição visual da música-aplicativo Moon, as pérolas são o resultado de reação natural de defesa sobre seu organismo contra invasores externos (como parasitas, areias ou vermes) que perfuram a concha dos moluscos e se alojam em seu manto (MUNDO ESTRANHO, 2011).

As pérolas aparecem como um Signo em Referência na letra musical da canção, no videoclipe de Moon e assim como na composição interativa de sua música-aplicativo (FIG. 7). Björk Ihes faz referência como suas "pérolas de adrenalina" - as quais os deuses lhe retiram ao cantar: "Como se as mornas mãos dos deuses / Viessem gentilmente e colhessem minhas pérolas de adrenalina / Pusessem-nas em suas bocas / E enxaguassem todo o medo / Nutrindo-as com com sua saliva / [...]" (BJÖRK, [2011], tradução do autor). 
Em relação ao videoclipe, as pérolas aparecem pela primeira vez enquanto Björk toca uma das melodias da canção de Moon em uma espécie de vestido de harpa no qual está trajada (em $1 \mathrm{~min} 23 \mathrm{seg}$ do videoclipe). É possível notar que as pérolas aparecem de modo gradual à medida que a melodia avança - servindo de um acompanhamento visual - assim como giram e mudam sua iluminação até que Björk [2011] $]^{3}$ recita "As if the healthiest pastime [...]" (em 1min53seg do videoclipe) e assim como ressurgem ao longo do videoclipe.

FIGURA 7 - As Pérolas da música-aplicativo "Moon”, como um "Signo em Referência"

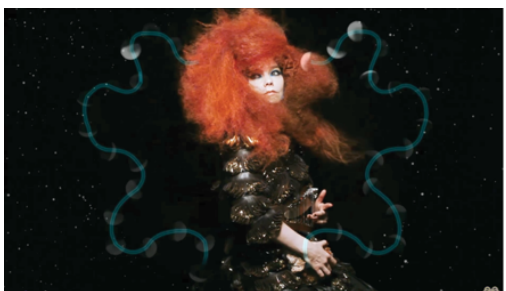

BJÖRK ENQUANTO TOCA UMA DAS MELODIAS EM UM VESTIDO DE HARPAS (1:23)

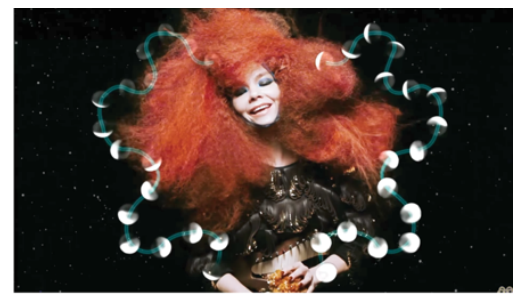

"As if the healthiest pastime / Is being in life-threatening circumtances" (1:53)

FONTE: Adaptado de Björk (2011). Disponível em:

https://www.youtube.com/watch?v=br2s0xJyFEM. Acesso em: 12 out. 2017. Elaborado pelo autor.

Para uma interpretação sobre aspectos poético-textuais, é necessário compreender que o hormônio da adrenalina é produzido e liberado no organismo em situações de excitação, estresse, nervosismo, cansaço físico e afins - provocando "reações de fuga" por meio da dilatação da pupila, sudoreses, tremores, dentre outros (BERNE, 2004 apud GONÇALVES, [2017]). Björk [2011] relata sobre os deuses atuarem como mentores e tranquilizadores de medos tidos pela cantora. $O$ ato de recolhimento dessas "pérolas de adrenalina" dá indícios sobre a generosidade e a solicitude dos deuses para que eles possam cessar aquilo que the aflige, assim como preencher as pérolas com calma e paz de espírito. É possível pensar no significado das pérolas como "[...] de adrenalina" quando contextualizadas a este hormônio: Björk sentia medo e a adrenalina é produzida a partir deste sentimento.

A adrenalina Ihe geraria desconforto e agitação, como um instinto de atenção sobre algo que lhe possa atingir. No entanto, os deuses vieram até ela, recolheram as pérolas com suas gentis e "mornas mãos" para que ela pudesse descansar e, com isto, a possível situação de alto estresse, como motivadora da produção do hormônio da adrenalina, é reforçada quando Björk recita "Como se o passatempo mais saudável / Fosse correr risco de morte" (ou sem uma adaptação mais poetizada e próxima ao literal, "circunstâncias de ameaça à vida"). Os deuses a fazem descansar para que possa renascer e ser feliz novamente, ressaltando, então, a metáfora de "regeneração" e "renascimento" - segundo BJÖRK, [2011], tradução do autor - e estabelecer um vínculo simbólico com a Lua e suas Fases Lunares, em um processo poético de renovação na vida da cantora.

\footnotetext{
3 “Como se o passatempo mais saudável [...] A melhor forma de se recomeçar [...] Arriscar tudo é o fim de tudo e o início de tudo" (BJÖRK, [2011]).
} 
A tradução icônica do Objeto-Pérola traduzido acontece mediante às analogias em estruturas e formas remetentes ao "Objeto Imediato" (o Objeto-Pérola original e seus atributos qualitativos). As semelhanças entre a forma arredondada, as cores, o brilho (e a variação sutil em relação ao sombreamento) estabelecem uma atribuição de referência direta a valores inerentes ao seu "referente" - a representação já existente e perceptível do Objeto-Pérola original e físico em ambiente marítimo. $O$ aspecto "paramórfico" da tradução icônica do Objeto-Pérola se dá por meio a utilização de formas similares (ou equivalentes) ao objeto original, ainda que estejam empregados em uma tradução com uma estrutura diferente (ou equivalente) em um outro sistema (PLAZA, 2001) (FIG. 8). Apesar de ser um hipoícone de "Imagem", o Objeto-Pérola traduzido tem estruturas representacionais equivalentes, de modo parcial, ao Objeto-Pérola original visto que não é uma reprodução fiel ao seu todo original.

FIGURA 8 - As Pérolas da música-aplicativo "Moon”, como um "Signo em Substituição"
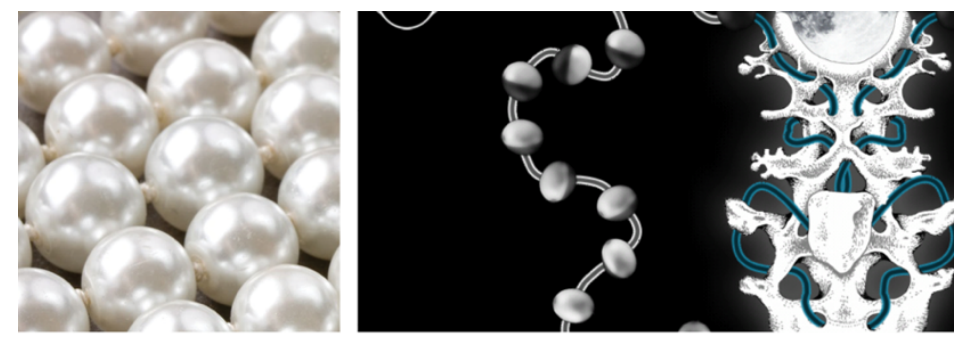

FONTE: Adaptado de http://miguelalcade.com.br/luxo/caracteristicas-das-perolas-oriente-e-brilho; Biophilia, Aplicativo, Google Play. Elaborado pelo autor.

Os aspectos qualitativos e estruturais são reforçados como um Signo em Substituição na tradução indicial do Objeto-Pérola e em seu relacionamento com o Objeto-Lua. O Objeto-Pérola traduzido possui partes de objetos originais (por exemplo, da própria pérola e da Lua) sendo deslocados como forma de manter a continuidade entre o que é original e o que é tradução, repostos em um novo meio (a linguagem visual interativa da música-aplicativo), gerando novos sentidos sobre sua representação por intermédio do novo meio que the acolhe. $O$ aspecto desta tradução é de ser "topológica-metonímica", visto que se trabalha com a noção parcial de estruturas em deslocamento para um novo contexto de linguagem sígnica (PLAZA, 2001).

A representação do Objeto-Pérola aponta para algo que Ihe é externo (a Pérola, a Lua e o Sol, ao ato de movimento ou modificação) devido à mudança de contrastes, de variação de iluminação e cores de si mesmo. Além disto, é importante ressaltar que a tradução indicial se resolve pela singularidade do Objeto-Pérola traduzido, sendo preciso perceber que a variação de contrastes e iluminação não possuem regularidade tão fiel a uma representação física com a variação referente à alteração de iluminação de um Objeto-Pérola original. O contraste de luz e sombra remetem de modo mais abstraído à variação de Fases Lunares (devido à estrutura e contrastes mais próximos ao Objeto-Lua original) - resultando que seja possível interpretar o Objeto-Pérola traduzido como miniluas em um processo de construção de um novo sentido (ou de "ressemantização"), em um novo contexto - o meio digital e interativo.

O Objeto-Pérola também apresenta um relacionamento com o Objeto-Harpa como um 
Signo em Substituição para a linguagem visual da música-aplicativo, em um processo de tradução simbólica. Para compreender a interação entre ambos os objetos em um processo tradutório, é preciso contextualizá-los à construção da composição musical da canção Moon.

De acordo com Dibben (2011), Björk se uniu ao engenheiro de áudio e estúdio Damian Taylor para transmitir a ideia de ciclos na natureza, por meio de um software de programação visual para o campo da Música (chamado de Max), o qual permite criar "padrões" ao conectar diferentes elementos. Como complemento, Dibben (2011) relata sobre o aplicativo e controladores digitais auxiliarem na utilização de compassos musicais não usuais, evitando também que se utilizassem métricas populares (as quais tendem ao uso de múltiplos de dois) e enfim usar uma métrica incomum: o compasso $17 / 8$.

Em Teoria Musical, compassos são, conforme Carlini (2005, p. 155), uma "unidade métrica constituída por representações de tempos musicais agrupados em porções iguais e que é separada da unidade seguinte por um travessão ou barra de compasso", tendo sua fórmula representada por meio de dois números ("um sobre o outro"). Considerando que Moon possui o compasso $\mathbf{1 7 / 8}$, o número superior (o primeiro) representa a quantidade de pulsos (uma "marcação regular constante", tal como segundos, minutos e horas) que cada compasso musical deve possuir em sua reprodução (CARLINI, 2005; DIBBEN, 2011;). Na composição de Moon, segundo Fig. 9, tem-se a soma "6+6+5" (resultando em 17) em sua notação musical - na seção "Score" da música-aplicativo - e este tipo de soma serve para facilitar a visualização e compreensão do compasso, assim como delimitar como a contagem é feita. O número inferior compreende a figura que será a unidade de medida para a divisão dos pulsos do compasso, ou seja, a figura de número 8 ("colcheia") valerá 1 pulso (ou "tempo") e, deste modo, para completar um compasso, usando 1 nota por pulso, é necessário usar 17 colcheias.

FIGURA 9 - O compasso rítmico musical 17/8 da canção "Moon"
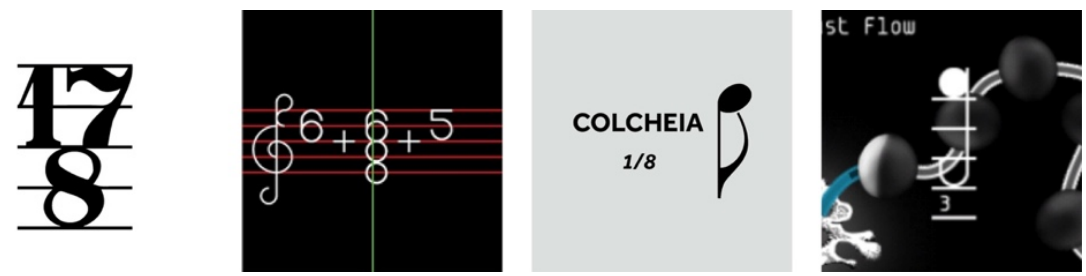

FONTE: Adaptado de Adaptado de Biophilia, Aplicativo, Google Play; Carlini (2005); Dibben (2011); Finale 2014, conjunto de programas, MAKEMUSIC Inc., 2017. Elaborado pelo autor.

A ressignificação do Objeto-Pérola, como um processo de Signo em Definição, ocorre por meio da tradução simbólica (em um vínculo com os Objetos e temáticas abordados no processo de Signo em Substituição). A disposição de diversos Objetos-Pérolas traduzidos na linguagem visual da música-aplicativo dá indícios sobre a interação proposta por Moon, à medida que determina signos simbólicos ao Objeto-Pérola na interface digital interativa. O Objeto-Pérola traduzido é disposto em repetição, resultando em 17 Objetos-Pérolas em cada lado do ObjetoMedula traduzido, ao pensar em um recorte simétrico e vertical da composição visual como um todo. 
A disposição de 17 Objetos-Lua traduzidos, em cada lado da composição visual, dá indícios de um relacionamento simbólico em referência ao compasso $17 / 8$, utilizado no instrumental de harpas da canção Moon. A ordenação visual - como signos indiciais - dos Objetos-Pérolas, repetidos diversas vezes, aponta para algo externo a si mesmo (ao compasso utilizado na composição musical) e institui uma ligação convencionada em uma inter-relação à estrutura musical (por intermédio de signos simbólicos, visto que o instrumental da canção não possui um vínculo estrutural com a representação imagética e visual do Objeto-Pérola traduzido e repetido).

A função das pérolas na música-aplicativo é de aumentar ou diminuir a altura de notas ao mover as luas, resultando na troca das Fases Lunares por meio do sombreamento e iluminação. A linguagem sonora é atrelada de modo simbólico à linguagem visual de Moon, mediante a utilização das harpas que compõem a estrutura musical da canção. O som da harpa é um símbolo convencional - em relação aos Signos em Referência da própria canção, letra musical e do videoclipe (em que Björk aparece tocando uma espécie de vestido de harpa). O vínculo entre a harpa e pérolas é instalado de modo arbitrário e instituído no Objeto-Pérola traduzido, visto que a compreensão sobre o relacionamento entre ambos ocorre por meio de um processo mais lógico e abstrato

Logo, a construção do signo sonoro-visual do Objeto-Pérola traduzido é arbitrária. A mudança de altura das notas só pode acontecer se o usuário entender que elementos compositivos servem como leis (como a mudança de contraste de cores, de iluminação, de movimento das pérolas ou o aparecimento de notações musicais), no contexto da músicaaplicativo, para que possa jogar a partir das regras estabelecidas. Com isto, delimitam e reforçam a metáfora de variação e de "renascimento" - por meio da representação de Fases Lunares (com base em Björk [2011]). O processo relacional e associativo do Objeto-Pérola traduzido dispõe consigo a articulação em conjunto de signos icônico-indiciais (de diferentes contextos), rumo à instauração de um signo simbólico e de aspecto sonoro-visual (pérolas com som de harpa e suas variações de altura de notas).

\section{Considerações Finais}

A motivação desta pesquisa surgiu a partir do fomento e curiosidade em entender como diversas referências podem se mesclar a um cenário musical e visual. A materialidade visual está sempre presente nos materiais de divulgação de um álbum musical (em sua capa, em seus videoclipes ou materiais promocionais), no entanto, as representações imagéticas e os diferentes simbolismos estabelecidos contemplam as ideias - em um primeiro momento - abstratas ou restritas às distintas imagens mentais dos criadores e criativos?

Flusser (2007) utiliza a etimologia da palavra "de-signar" - a qual é tanto um substantivo quanto um verbo - para refletir sobre o conceito de design. A palavra latina "signum" tem seu significado como propósito, plano, esquema maligno, forma, fraude, conspiração; por outro lado o verbo significa simular, projetar, esquematizar, configurar, proceder de modo estratégico. 0 design é um alicerce e está na base de toda cultura, visto que serve como um meio de "enganar" a natureza das coisas mediante o uso da técnica. O Biophilia utiliza do suporte em mídia eletrônica, em conjunto da linguagem visual e sonora, para combinar aspectos qualitativos destas matrizes e reconfigurar - assim como simular - uma nova linguagem (um aplicativo didático e interativo para fins educacionais).

A adoção de diferentes códigos, advindos de diferentes contextos, concede ao expectador 
a possibilidade de interpretar diferentes estruturas em um mesmo objeto posto em tradução. 0 Objeto-Pérola traduzido possui qualidades que o representa como referência a uma pérola original, do mesmo modo em que também se torna compreensível como uma minilua - por também adquirir aspectos de outro objeto e contexto originais - para que possa, então, resultar na inter-relação simbólica e simultânea entre linguagens (pérolas que mudam a altura de notas musicais quando interagidas pelo usuário). Logo, a recombinação destes diferentes signos e objetos se baseia na substituição. A leitura e utilização de códigos imagéticos tradicionais acontecem por meio da imaginação - sendo resultado de aplicação de códigos específicos, podendo ser lidas por qualquer um que possua familiaridade e repertório em comum ao objeto. $\mathrm{O}$ suporte eletrônico (um aplicativo interativo em multimídia) é um "performatizador" que serve como potencialização do processo de "retradução" (FLUSSER, 2007; PLAZA, 2001).

O Biophilia (2011) utiliza um denso repertório, proveniente de diferentes contextos sígnicos e científicos, atraindo a atenção acerca da compreensão sobre relações construtivas de sentido entre música e composição visual em um processo de tradução de linguagens, por meio do suporte em âmbito digital (em multimídia e hipermídia) - retomando e potencializando a comunicação por intermédio de imagens. A "transmutação" sígnica de Plaza (2001), norteada pela teoria semiótica de Peirce, pode ser relacionada ao processo de atribuição de códigos e símbolos a imagens em um contexto social, refletidas por Flusser (2007). Sendo usadas - de modo primitivo, nos primórdios históricos - como expressão a desejos e inspirações, caminhando ao aprimoramento comunicativo de uma escrita linear ("pensamento-em-linha"), para que possam, enfim, direcionar os novos meios tecnológicos como mediadores de imagens por meio do imaginário.

Para o pensamento analítico do artigo, definiu-se a divisão de Moon em Eixos Temáticos: Astronomia; Oceanografia (Biológica e Física); Biologia (Anatomia e Entomologia); Psicologia e Teoria Musical - focando-se em discorrer a respeito do Eixo Temático da Oceanografia (Biológica). Estes elementos foram dispostos em um pensamento narrativo em consideração ao sistema de Operação Tradutória desenvolvido (Signo em Referência; Signo em Substituição e Signo em Definição) - tendo em mente a apropriação de códigos de diferentes meios, suas interações, e a concretização de um ressignificado. A interpretação do Objeto-Pérola traduzido, como um reforço às metáforas de "renovação" e "renascimento" (sugeridas por Björk [2011]), é fruto de um processo icônico, indicial, e enfim, simbólico de diferentes signos postos em uma nova tradução gerando, de modo incessante, novos significados. Logo, as três tipologias de traduções sígnicas são inter-relacionais em um processo de "remessa", isto é, não atuam de modo isolado e não são o objeto em si, mas sim uma constante transformação em outros signos, a fim de criarem novos sentidos para "Interpretantes" (PLAZA, 2001).

\section{Referências}

BIOPHILIA EDUCATIONAL. LEARNTEACH: Biophilia in a school setting. Ministry for Education, Science \& Culture e Biophilia Education, [2017]. Disponível em:<http://biophiliaeducational.org/> Acesso em: 10 abr. 2017.

BJÖRK. Moon - Infos et Paroles. Bjork.fr, [2011]. Disponível em: <http://bjork.fr/Moon>. Acesso em: 1 out. 2017.

BJORK.FR. Biophilia - bjork.fr. Bjork.fr, [2011]. Disponível em: <http://bjork.fr/-Biophilia-special-> Acesso em: 18 maio 2017. 
CARLINI, Álvaro L. R. S. A música e a matemática. In: MAIA, Eny Marisa (Coord.); MURRIE, Zuleika de Felice (Coord.). Arte: Projeto Escola e Cidadania para Todos. São Paulo: Editora do Brasil, 2005.

DAZED \& CONFUSED. Björk Unveils Live Residency. Dazed \& Confused, 2011. Disponível em: $<$ http://dazeddigital.com/music/article/10006/1/bjork-unveils-liveresidency>. Acesso em: 8 abr. 2017.

DIBBEN, Nicola. Biophilia - The Manual Edition. Wellhart Ltd., 2011. Disponível em: <http://bjork.fr/Biophilia-Manual>. Acesso em: 8 abr. 2017.

DICIO. Definição - Dicionário Online de Português. Dicio, Dicionário Online de Português, 2017. Acesso em: 1 set. 2017. Disponível em: <https://dicio.com.br/definicao/> .

FLUSSER, Vilém. O mundo codificado: por uma filosofia do design e da comunicação. Vilém Flusser, organizado por Rafael Cardoso. São Paulo: Cosac Naify, 2007. 244 p.

GONÇALVES, Fabiana Santos. Adrenalina. InfoEscola, [2017]. Disponível em: < http://infoescola.com/hormonios/adrenalina/> Acesso em: 1 out. 2017.

MILLER, Clair Cain. Bjork, Icelandic Singer and...Venture Capitalist? The New York Times. Disponível em: <https://nyti.ms/2lafksd> Acesso em: 10 abr. 2017.

MUNDO ESTRANHO. Como a ostra produz a pérola? Redação Mundo Estranho, 2011. Acesso em 24 de set. 2017. Disponível em <https://mundoestranho.abril.com.br/mundo-animal/como-aostra-produz-a-perola/>.

MICHAELIS, Dicionário Brasileiro da Língua Portuguesa. Referência | Michaelis On-Line. Editora Melhoramentos Ltda., 2017. Acesso em: 1 set. 2017. Disponível em:

<http://michaelis.uol.com.br/moderno-portugues/busca/portuguesbrasileiro/referencia/> SANTAELLA, Lucia. Matrizes da linguagem e pensamento: sonora, visual, verbal: aplicações na hipermídia. 3 ed. São Paulo: Editora Iluminuras Ltda, 2001. 432 p.

SMITH, Caspar Llewellyn. Bjork develops Biophilia while Damon Albarn shuns Tudor dress for festival. The Guardian, 2011. Disponível em:

<https://theguardian.com/culture/2011/mar/18/bjork-albarn-manchester-international-festival>. Acesso em: 11 abr. 2017.

SNIBBE, Scott. björk: biophilia: tour app tutorial. YouTube, 2012. Disponível em: https://youtube.com/watch?v=n8c0x6dO2bg\&. Acesso em: 10 abr. 2017.

Björk: Biophilia. Scott Snibbe, 2011. Disponível em:

<https://snibbe.com/apps\#/biophilia/>. Acesso em: 16. abr. 2017.

STOSUY, Brandon. Stereogum Q\&A: Björk Talks Biophilia. Stereogum, 2011. Acesso em: 27 ago. 2017. Disponível em: <http://stereogum.com/744502/stereogum-qa-bjork-talksbiophilia/franchises/interview/>

PLAZA, Julio. Tradução Intersemiótica. São Paulo: Perspectiva, 2001. 211 p.

TURIN, Roti Nielba. Aulas: introdução ao estudo das linguagens. São Paulo: Annablume, 2007.

UERJ. OCEANOGRAFIA BIOLÓGICA. UERJ, Faculdade de Oceanografia (FAOC), [2017]. Acesso em 24 de set. 2017. Disponível em <http://oceanografia.uerj.br/ocnbio/index.php>. 